$$
\text { CONF-9709101--1 }
$$

Note: This is a preprint of a paper being submitted for publication. Contents of this paper should not be quoted nor referred to without permission of the author(s).

To be Presented at:

7th International Conference on the Structure

of Non-Crystalline Materials

Sardegna, Italy

Sept. 15-19, 1997

\title{
Intermediate-Range Order in Simple Metal-Phosphate Glasses: The Effect of Metal Cations on the Phosphate Anion Distribution
}

\author{
B.C. Sales, L. A. Boatner, and J. O. Ramey \\ Solid State Division \\ Oak Ridge National Laboratory \\ Oak Ridge, Tennessee 37831-6056
}

\author{
June 1997 \\ "The submitted manuscript has been authored by a contractor of the \\ U.S. Government under contract DE-ACO5-S60R22464. Accordingly, \\ U.S. Government under coniract DE-ACDS-900R22464. Accordingly, \\ the U.S. Government retains a nonexclusive, rayalty-ree license to \\ pubish or reproduce the published form of this contribution, or aliow \\ Prepared by \\ Solid State Division \\ Oak Ridge National Laboratory \\ P.O. Box 2008 \\ Oak Ridge, Tennessee 37831-6056 \\ managed by \\ LOCKHEED MARTIN ENERGY RESEARCH CORP. \\ for the \\ U.S. DEPARTMENT OF ENERGY \\ under contract DE-AC05-96OR22464
}

This research was sponsored by the Oak Ridge National Laboratory, managed by Lockheed Martin Energy Research Corp., for the U.S. Department of Energy, under contract DE-AC05-96OR22464. 


\section{DISCLAMIER}

Portions of this document may be illegible in electronic image products. Images are produced from the best available original document. 


\title{
INTERMEDIATE-RANGE ORDER IN SIMPLE METAL-PHOSPHATE GLASSES: THE EFFECT OF METAL CATIONS ON THE PHOSPHATE ANION DISTRIBUTION ${ }^{\star}$
}

\author{
B. C. Sales, L. A. Boatner and J. O. Ramey, Solid State Division, Oak Ridge National \\ Laboratory, Oak Ridge TN 37831-6056.
}

The technique of high-performance liquid chromatography (HPLC) has been used to probe the phosphate anion distribution in a variety of metal phosphate glasses including glasses made with trivalent metal cations ( $\mathrm{Al}, \mathrm{In}, \mathrm{Ga}, \mathrm{La}$ ). The composition of each glass was chosen so that the average phosphate chain length was between 2 and $4 \mathrm{PO}_{4}$ tetrahedra. The widths of the resulting phosphate anion distributions were determined directly from an analysis of the HPLC chromatograms. Literature values for the free energy of formation of the crystalline metal-orthophosphate compounds with respect to $\mathrm{P}_{2} \mathrm{O}_{5}$ and the metal oxide, were compared to the chromatogram widths. It was found that the smaller the energy of formation, the wider the distribution of phosphate chains, and the greater the ease of glass formation.

\section{Introduction}

Metal oxides are added to the "simple" glass forming oxides $\left(\mathrm{SiO}_{2}, \mathrm{P}_{2} \mathrm{O}_{5}, \mathrm{~B}_{2} \mathrm{O}_{3}\right.$ or $\mathrm{GeO}_{2}$ ) to make the properties of the resulting glass suitable for a particular application. It is well known that the addition of certain metal oxides greatly hinders glass formation while others have a minimal effect. In a simple binary oxide glass ( e.g. $\mathrm{Na}_{2} \mathrm{O} \cdot \mathrm{SiO}_{2}$ ), where only one type of metal cation has been added, what determines how a particular metal cation will effect the ease of glass formation? Several empirical rules have been proposed that relate the ease of glass formation to the metal-cation's ionic size, field strength, net charge, electronegativity, etc. One of the more interesting ideas was proposed by Meadowcroft and Richardson (MR) in 1965 [1]. For several monovalent and divalent phosphate glasses, they showed by using solution calorimetry and chromatographic techniques, that the ease of glass formation could be related to the heat of formation of the solid glass (or crystal) with respect to $\mathrm{P}_{2} \mathrm{O}_{5}$ and the metal oxide. The smaller the heat of formation, the wider the distribution of phosphate chains, and the greater the ease of glass formation.

In glass technology today, the parameter that is most commonly used to classify metal cations is Dietzel's [2,3] field strength. This parameter measures the electrostatic energy between the metal cations and the neighboring oxygen anions. Field strength is particularly useful in parameterizing the physical properties of a multicomponent glass. For example, Hayden et. al. [4] found that thermal conductivity, thermal expansion, Young's modulus and 
the index of refraction systematically varied with the average field strength in complicated multicomponent laser glasses. Although field strength is simple to calculate for a particular glass, the physical relationship between this parameter and the ease of glass formation in a binary metal phosphate glass is not obvious.

The free energy of formation of a crystalline solid provides a measure of the thermodynamic driving force for the creation of a particular compound. For example, if one mole of $\mathrm{Na}_{2} \mathrm{O}$ is reacted with two moles of $\mathrm{SiO}_{2}$, with respect to the oxides, the free energy of formation, $\Delta G$, under standard conditions $[5,6]$ is $-238 \mathrm{~kJ} / \mathrm{mole}$ of $\mathrm{Na}_{2} \mathrm{Si}_{2} \mathrm{O}_{5}$. It has been hypothesized since the early days of glass science that a small value for the free energy of formation implied that glasses made near this composition should exhibit a wider distribution of silicate anions and hence should form glasses more easily. This hypothesis is difficult to test in silicate, borate and germanate glasses, because of the inability to obtain reliable information about the distribution of anions in these glasses, and the tendency of these glasses to phase separate [7]. Precise information about the distribution of phosphate anions in most metal phosphate glasses, however, can be determined using high-performance liquid chromatography (HPLC). Phosphate glasses also show less of a tendency to phase separate and thus provide model systems on which to test some fundamental ideas about the role of various metal cations in glass formation.

MR [1] showed that the heat of formation (enthalpy) of some binary phosphate crystals and glasses correlated well with the ease of glass formation. Metal phosphate glasses with small heats of formation, had broader distributions of phosphate anion chains, and hence were easier to form as glasses. The purpose of the present work is to test the validity of this idea on a wider range of metal phosphate glasses. The free energy of formation with respect to the oxides is used to measure the thermodynamic driving force rather than the heat of formation. For solid-solid reactions of the type that characterize the reaction of $\mathrm{P}_{2} \mathrm{O}_{5}$ with a metal oxide, there is very little difference between these two thermodynamic quantities.

\section{Experimental}

The metal-phosphate glasses were prepared by the reaction of $\mathrm{NH}_{4} \mathrm{H}_{2} \mathrm{PO}_{4}$ with the metal oxide or carbonate (Metal cations: $\mathrm{Li}, \mathrm{Na}, \mathrm{Ca}, \mathrm{Ba}, \mathrm{Zn}, \mathrm{Pb}, \mathrm{Al}, \mathrm{Ga}, \mathrm{In}, \mathrm{Al}, \mathrm{La}, \mathrm{Y}, \mathrm{Sc}$ ). Appropriate amounts of the reactants were intimately mixed in a ball mill, prereacted at $500^{\circ} \mathrm{C}$ for several hours, melted in a platinum crucible at temperatures between 800 and $1450{ }^{\circ} \mathrm{C}$ for 1-3 hours and then quenched onto a cold copper plate. At each stage of the synthesis the weight was carefully monitored since glasses that melted at temperatures above $1250-1300$ ${ }^{\circ} \mathrm{C}$ tended to lose $\mathrm{P}_{2} \mathrm{O}_{5}$. The compositions of the glasses were checked using energy 
dispersive $x$-ray analysis, the measured weight loss, and the average chain length determined from the chromatograms. To obtain the best results from the HPLC measurements, phosphate glasses were prepared with average chain lengths between 2 and 4 .The Sc and $Y$ phosphates glasses could not be prepared at temperatures below $1450^{\circ} \mathrm{C}$ and hence were not investigated. What appeared to eye to be a $\mathrm{Ba}$ phosphate glass, had small crystalline inclusions of $\mathrm{Ba}_{2} \mathrm{P}_{2} \mathrm{O}_{7}$ that were evident in the chromatograms and in powder $\mathrm{x}$-ray diffraction measurements.

The HPLC system and the evidence for the validity of the HPLC technique have been discussed previously [8-10]. Phosphate glasses and crystals that dissolve faster than about $10^{-11}\left(\mathrm{~g} / \mathrm{cm}^{2}-\mathrm{s}\right)$ at $25^{\circ} \mathrm{C}$ can be reliably studied using the HPLC technique. This includes almost all metal phosphate glasses, in contradiction to "conventional wisdom" [7]. Briefly, the phosphate glasses are partially dissolved in a $0.22 \mathrm{M} \mathrm{NaCl}$ and $0.005 \mathrm{M} \mathrm{Na4EDTA}$ aqueous solution which has a pH of 10 . The phosphate glasses can be viewed as consisting of chains of corner-linked $\mathrm{PO}_{4}$ tetrahedra that are bonded to each other via the metal cations. Only the bonds between the metal cations and the non-bridging oxygen are severed during the dissolution process. This results in the transport of entire phosphate chains into solution. Once the chains are in solution, they are stable against hydrolysis for several days. The longer the phosphate chain, the larger the charge, and the more strongly the chain is bound to an anion exchange column. As the $\mathrm{NaCl}$ concentration is increased in the column, the shortest phosphate chains are released first (orthophosphate anion), followed by the next shortest (pyrophosphate anion), etc. The column we normally use for phosphate chain analysis can separate chains up to $13 \mathrm{PO}_{4}$ tetrahedra in length as well as cyclic phosphate anions such as tri- and tetra-metaphosphate. Other columns are available that can separate chains up to 35 $\mathrm{PO}_{4}$ tetrahedra in length. After the phosphate anions leave the column, they are hydrolyzed to orthophosphate anions in an acidic solution at elevated temperatures, and then combined with a molybdenum salt to form a complex ion that absorbs light strongly in the blue. The optical adsorption of the effluent stream is measured versus time, and the area under each of the absorption peaks is proportional to the amount of phosphorus in the glass that comes from a phosphate chain of a particular length. The position of each of the absorption peaks, corresponding to a specific phosphate anion, is calibrated using crystalline phosphate standards. As long as the dissolution of the glass is significantly faster than the rate of direct hydrolysis of P-O-P bonds, this technique provides quantitative information about the distribution of phosphate chains in the glass.

\section{Results and Discussion}


Typical chromatograms are shown in figures 1 and 2 for sodium, zinc, aluminum, gallium, indium and lanthanum phosphate glasses. The area under each peak, labeled $P_{n}$, is proportional to the amount of phosphorus present as a phosphate anion consisting of $n$ cornerlinked $\mathrm{PO}_{4}$ tetrahedra with a formal charge of $-(n+2)$, i.e. $\left(\mathrm{P}_{n} \mathrm{O}_{3 n+1}\right)^{-(n+2)}$. The average phosphate chain lengths, nav, determined from the chromatograms, were in good agreement with the chain lengths expected from the glass compositions. In addition to the linear phosphate anions (Fig. 1), for the aluminum phosphate glass a small quantity of the trimetaphosphate ring anion $\left(\mathrm{P}_{3 \mathrm{~m}}\right)$ was also detected. Trimetaphosphate and tetrametaphosphate ring anions were also present in the lanthanum and indium phosphate glasses (Fig 2). In Fig. 1 the distribution of phosphate anions in the sodium phosphate glass clearly is narrower than the distribution from either of the other two phosphate glasses. However, to compare the aluminum and zinc phosphate anion distributions requires a more quantitative analysis of the chromatograms..

If the average phosphate chain length is fixed (composition fixed), the widest distribution of anions is given by the Flory distribution ${ }^{11}$. In a Flory distribution, reactions of the type:

$$
2\left(P_{n} O_{3 n+1}\right)^{-(n+2)} \Leftrightarrow\left(P_{n+1} O_{3 n+4}\right)^{-(n+3)}+\left(P_{n-1} O_{3 n-2}\right)^{-(n+1)}
$$

have equilibrium constants, $K_{n}$, equal to 1 . Where $K_{n}$ is given by:

$$
K_{n}=\left[\left(P_{n+1} O_{3 n+4}\right)^{-(n+3)}\right] \cdot\left[\left(P_{n-1} O_{3 n-2}\right)^{-(n+1)}\right] /\left[\left(P_{n} O_{3 n+1}\right)^{-(n+2)}\right]^{2}
$$

In disproportionation reactions of the type shown in eq. (1), the charge, the phosphorus concentration, and the oxygen concentration all are preserved. An equilibrium constant of one implies that $\Delta G=0$ for eq. (1). All of the phosphate anion distributions are narrower than the Flory distribution primarily because the equilibrium constants, $K_{n}$, are less than 1 for $n=2,3$ or 4 . For longer chains (larger $n$ ),$K_{n} \cong 1$. $K_{n}$ values less than 1 corresponds to endothermic enthalpy changes associated with reaction (1). For a variety of alkali and alkaline earth phosphate glasses, MR found $K_{n}$ to be independent of the average phosphate chain length. This implies that one way of comparing the widths of the phosphate anion distributions from glasses with different average chain lengths, is to compare the values for $K_{n}$. As $n$ is increased,$K_{n}$ should approach 1 more quickly in metal phosphate glasses that form easily. 
Figure 3 shows the values of $\mathrm{K}_{2}, \mathrm{~K}_{3}$, and $\mathrm{K}_{4}$ obtained from the chromatograms of various metal phosphate glasses. The ordering of the cations on the abscissa is in accordance with the free energy of formation of the crystalline orthophosphates with respect to the oxides (Fig 4). $\mathrm{Na}_{3} \mathrm{PO}_{4}$ has the largest free energy of formation, and $\mathrm{AlPO}_{4}$ the smallest. No free energy data could be found for $\mathrm{InPO}_{4}, \mathrm{GaPO}_{4}$ or $\mathrm{LaPO}_{4}$, so these cations were placed on the abscissa such that the $K_{n}$ values formed a smooth curve. The free energy of formation (per mole of atoms) of $\mathrm{GaPO}_{4}$ should be close to that of $\mathrm{Zn}_{3}\left(\mathrm{PO}_{4}\right)$, and the formation energy for InPO 4 and $\mathrm{LaPO}_{4}$ should be similar to that of $\mathrm{AlPO}_{4}$. The width of the phosphate distributions increase as the metal cation is changed from $\mathrm{Na}$ to La, suggesting that metal phosphate glasses with smaller formation energies do indeed form glasses more easily as was suggested by MR. Although the above analysis only considered the energy of formation of crystalline orthophosphates, MR 1 showed for the alkali and alkaline earth phosphate glasses, that this conclusion also applied if other crystalline phosphates were considered (such as pyrophosphates).

Finally, it is interesting to compare (Table 1) the classification of metal cations in phosphate glasses using the Dietzel field strength parameter, and the free energy of formation of the orthophosphates. Using Dietzel's classification, all monvalent cations have smaller field strengths than divalent cations which in turn are smaller than all trivalent cations. The metal cation classification scheme using free energy is similar to field strength but the cations are not simply grouped according to charge. The relative ordering within the alkalis (or within the alkaline earths) is the same in both schemes. However, some alkaline earths, such as Ba or $\mathrm{Sr}$, have larger free energy values than the alkali $\mathrm{Li}$. This is in agreement with our experimental observation that $\mathrm{Ba}$ phosphate glasses were more difficult to prepare than Li phosphate glasses. It would be interesting to see what other physical properties (such as Young's modulus or the thermal conductivity) varied systematically with free energy of formation values.

\section{Conclusions}

The distributions of phosphate anions (chains) were measured for a variety of metal-phosphate glasses using the technique of HPLC. From each chromatogram, equilibrium constants, $K_{n}$, (eq. 2) were calculated for the metal phosphate glass. For a given metal phosphate glass, the more rapidly $K_{n}$ approached 1 with increasing $n$, the wider the distribution of phosphate anions, and the greater the ease of glass formation. The ease of glass formation correlated well with the literature values for the free energy of formation of the crystalline orthophosphates, measured with respect to $\mathrm{P}_{2} \mathrm{O}_{5}$ and the metal oxide. The ease of glass formation did not correlate as well with the metal-oxygen field strength. 


\section{Acknowledgments}

Research supported by the Division of Materials Sciences, U. S. Department of Energy under Contract No. DE-AC05-96OR22464. Oak Rldge National Laboratory is managed by the Lockheed-Martin Energy Research Corporation.

\section{References}

[1] T. R. Meadowcroft and F. D. Richardson, Trans. Faraday Soc. 61 (1965) 54.

[2] A. Z. Dietzel, Electrochem. 48 (1942) 9.

[3] W. Vogel, Chemistry of Glass, (The American Ceramic Society, Columbus, Ohio) $1985 \mathrm{p}$. 38.

[4] J. S. Hayden, Y. T. Hayden, and J. H. Campbell, SPIE Vol 1277, High Powered Lasers and Applications (SPIE Publications, Bellingham Washington, 1990), p 121.

[5] J. A. Dean, Lange's Handbook of Chemistry (McGraw Hill, New York, 1992), sections 4.5 and 6.1 .

[6] J. R. Van Wazer, Phosphorus and Its Compounds: Chemistry, Vol 1 (Interscience, New York, 1980) p. 889.

[7] W. Vogel, Chemistry of Glass (American Ceramic Society, Inc. Columbus, Ohio, 1985) p. 125.

[8] B. C. Sales, R. S. Ramsey, J. B. Bates, L. A. Boatner, J. Non-Cryst. Solids, 87 (1986) 137.

[9] B. C. Sales, J. O. Ramey, J. C. McCallum, and L. A Boatner, Phys. Rev. Lett. 62 (1989) 1138.

[10] B. C. Sales, B. C. Chakoumakos, L. A. Boatner, and J. O. Ramey, J. Non-Cryst. Solids 159 (1993) 121.

[11 ] J. Flory, Amer. Chem. Soc. 64 (1942) 2205 
TABLE I Classification of the metal cations in a simple phosphate glass by Dietzel's field strength parameter [3] or by the free energy of formation of the metal orthophosphate [5,6] with respect to the oxides. "Approximate values for the energy of formation have been estimated for $\mathrm{Ga}, \mathrm{La}$, and In orthophosphates using the equilibrium constants shown in Fig. 3.

Cation (Field Strength)

Cation(Free Energy of Formation)

( $\mathrm{kJ} / \mathrm{mole}$-atoms)

$\begin{array}{lll}\mathrm{K} & (0.13) & \mathrm{K}(89) \\ \mathrm{Na} & (0.19) & \mathrm{Ba}(79) \\ \mathrm{Li}(0.23) & \mathrm{Na}(70) \\ \mathrm{Ba} & (0.26) & \mathrm{Sr}(65) \\ \mathrm{Pb} & (0.27) & \mathrm{Li}(56) \\ \mathrm{Sr} & (0.28) & \mathrm{Ca}(55) \\ \mathrm{Ca} & (0.33) & \mathrm{Mg}(45) \\ \mathrm{Mg} & (0.45) & \mathrm{Pb}(38) \\ \mathrm{Mn}(0.49) & \mathrm{Mn}(31) \\ \mathrm{Zn} & (0.50) & \mathrm{Ga}(30)^{*} \\ \mathrm{La} & (0.54) & \mathrm{Zn}(27) \\ \mathrm{In} & (0.67) & \mathrm{Al}(19) \\ \mathrm{Fe} & (0.76) & \mathrm{La}(19)^{*} \\ \mathrm{Ga} & (0.78) & \mathrm{In}(19)^{\star} \\ \mathrm{Al} & (0.84) & \mathrm{Fe}(14)\end{array}$

\section{DISCLAIMER}

This report was prepared as an account of work sponsored by an agency of the United States Government. Neither the United States Government nor any agency thereof, nor any of their employees, makes any warranty, express or implied, or assumes any legal liability or responsibility for the accuracy, completeness, or usefulness of any information, apparatus, product, or process disclosed, or represents that its use would not infringe privately owned rights. Reference herein to any specific commercial product, process, or service by trade name, trademark, manufacturer, or otherwise does not necessarily constitute or imply its endorsement, recommendation; or favoring by the United States Government or any agency thereof. The views and opinions of authors expressed herein do not necessarily state or reflect those of the United States Government or any agency thereof. 


\section{Figure Captions}

Figure 1. Chromatograms from metal phosphate glasses made with a monovalent ( $\mathrm{Na})$, a divalent $(\mathrm{Zn})$, or a trivalent (Al) metal cation. The compositions of the glasses are Na1.6PO3.3, $\mathrm{Zn} 0.75 \mathrm{PO}_{3.25}$, and $\mathrm{Al}_{0.6} \mathrm{PO}_{3.4}$. The area under each peak labeled $\mathrm{P}_{\mathrm{n}}$ is proportional to the amount of phosphorus present in the glass in the form of $n$ corner-linked $\mathrm{PO}_{4}$ tetrahedra (anions of form $\left.\left(\mathrm{P}_{n} \mathrm{O}_{3 n+1}\right)^{-(n+2)}\right)$. Cyclic trimetaphosphate anions, $\mathrm{P}_{3 m}$, also were detected in the aluminum phosphate glass.

Figure 2. Chromatograms from metal phosphate glasses made with gallium, indium or

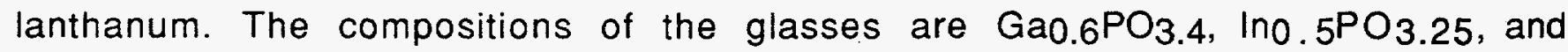
La0.52 $\mathrm{PO}_{3.28}$. The area under each peak labeled $P_{n}$ is proportional to the amount of phosphorus present in the glass in the form of $n$ corner-linked $\mathrm{PO}_{4}$ tetrahedra (anions of form $\left.\left(\mathrm{P}_{n} \mathrm{O}_{3 n+1}\right)^{-(\mathrm{n}+2)}\right)$. Cyclic trimetaphosphate anions, $\mathrm{P} 3 \mathrm{~m}$, and tetrametaphosphate anions, $P_{4 m}$, also were detected in the indium and lanthanum phosphate glasses.

Figure 3. Equilibrium constants determined from the chromatograms for reactions illustrated in eq. (1) versus the metal cation. The ordering of the cations on the abscissa is in accordance with the free energy of formation of the crystalline orthophosphates with respect to the oxides.

Figure 4. Free energy of formation of the crystalline orthophosphates with respect to $\mathrm{P}_{2} \mathrm{O}_{5}$ and the metal oxide. A large energy of formation implies a strong driving force for crystallization and a narrow distribution of phosphate anions in the glass. A small energy of formation facilitates the formation of a glass with a wide distribution of phosphate anions. 

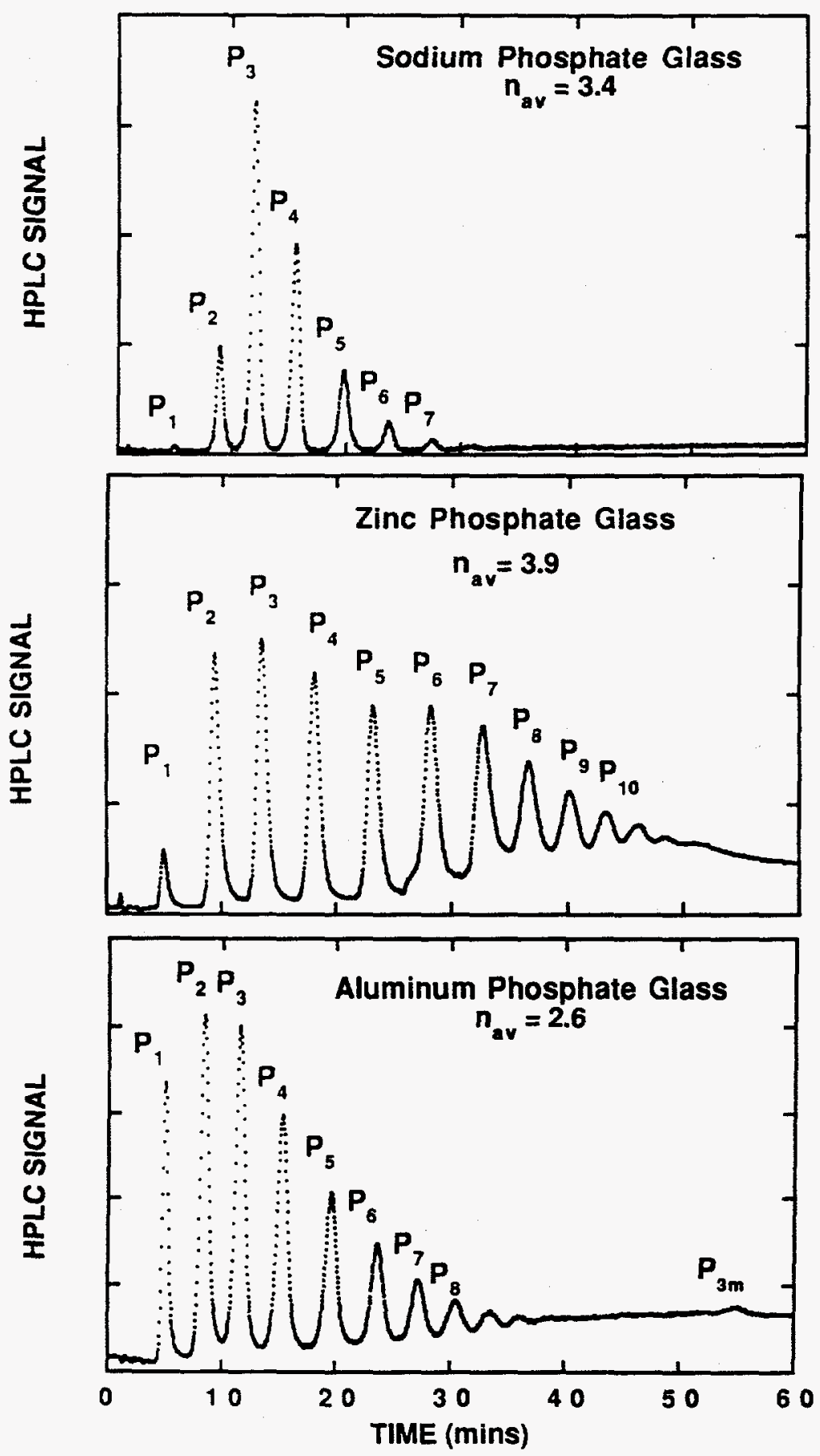

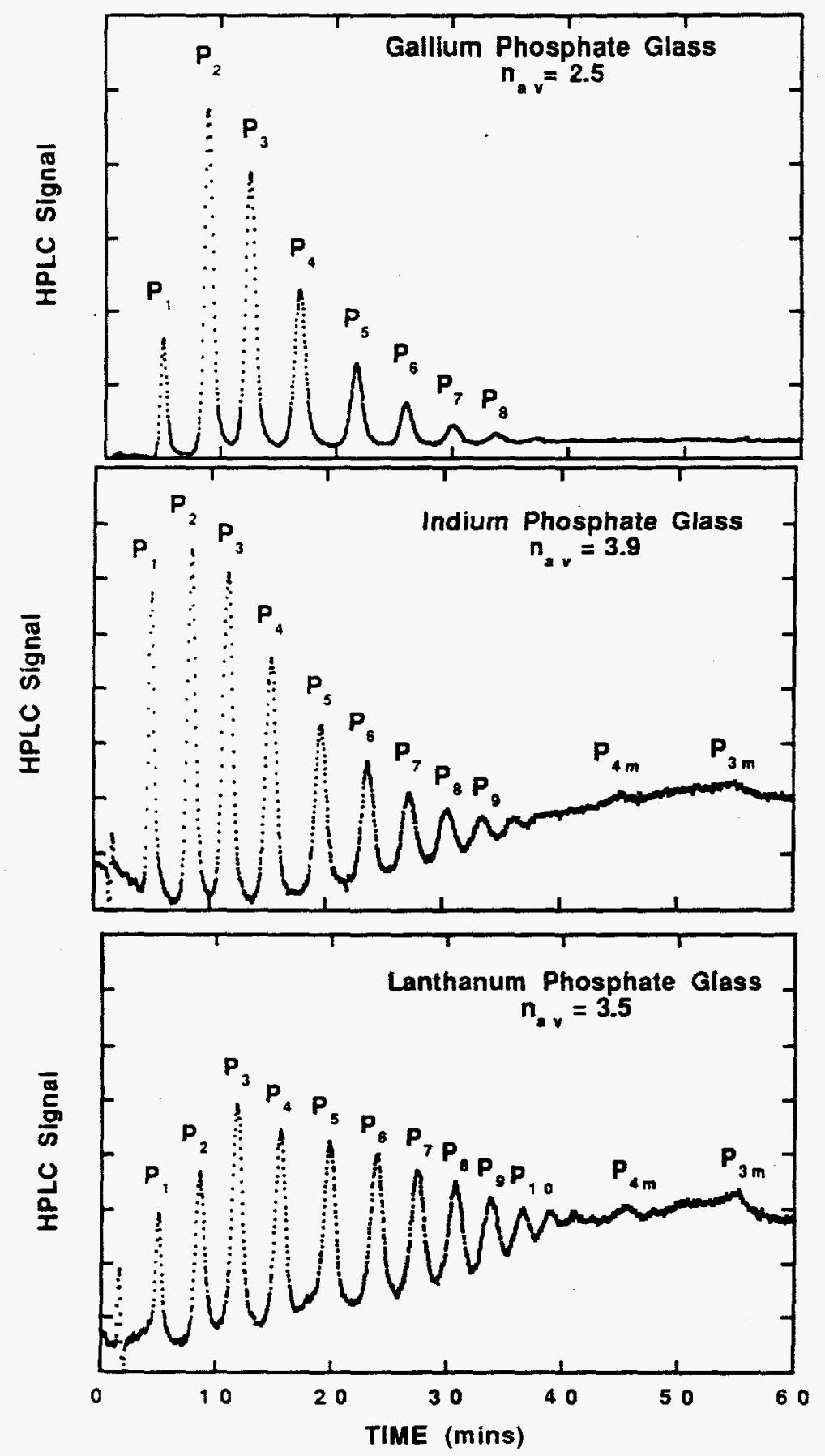

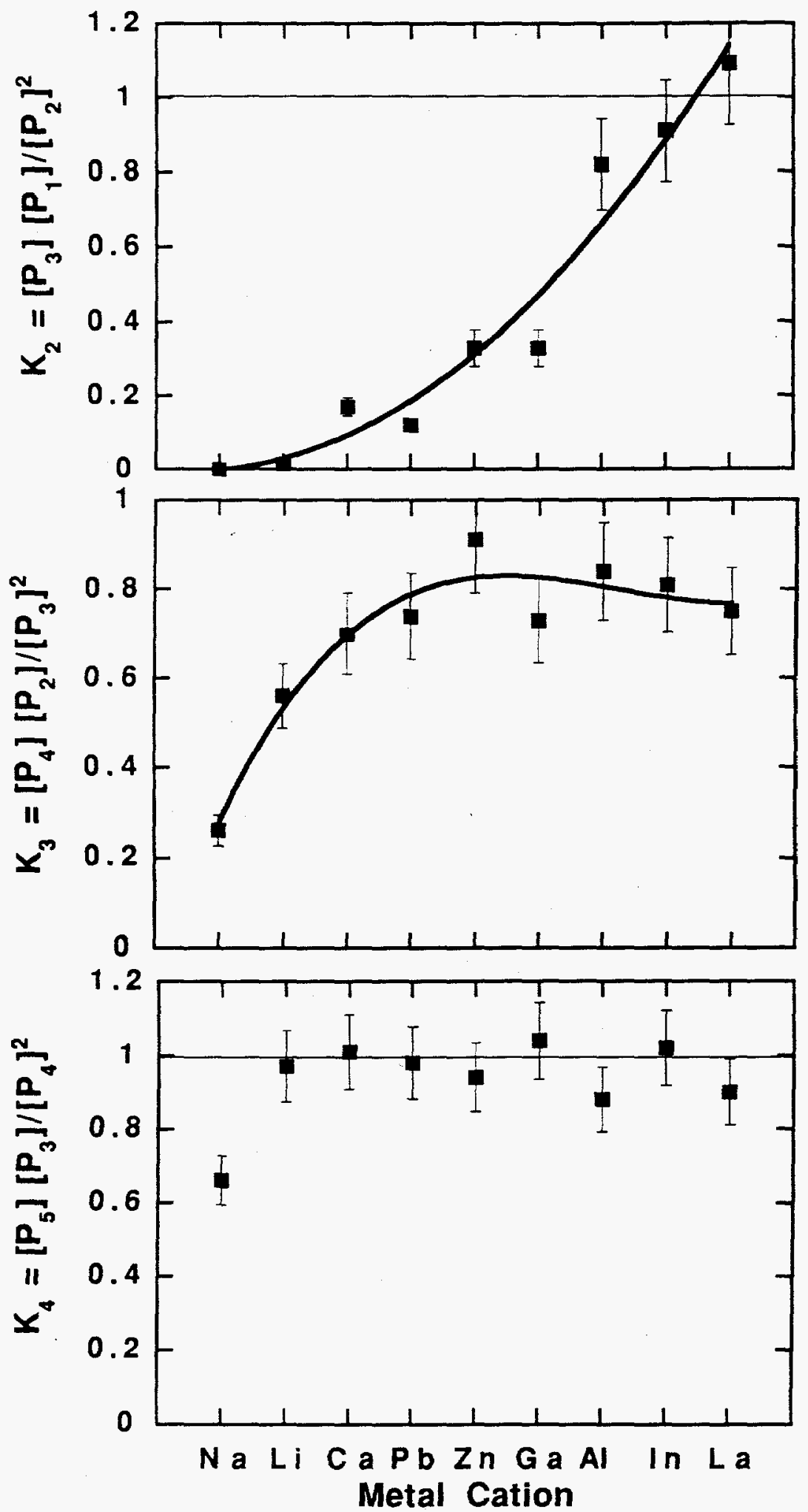


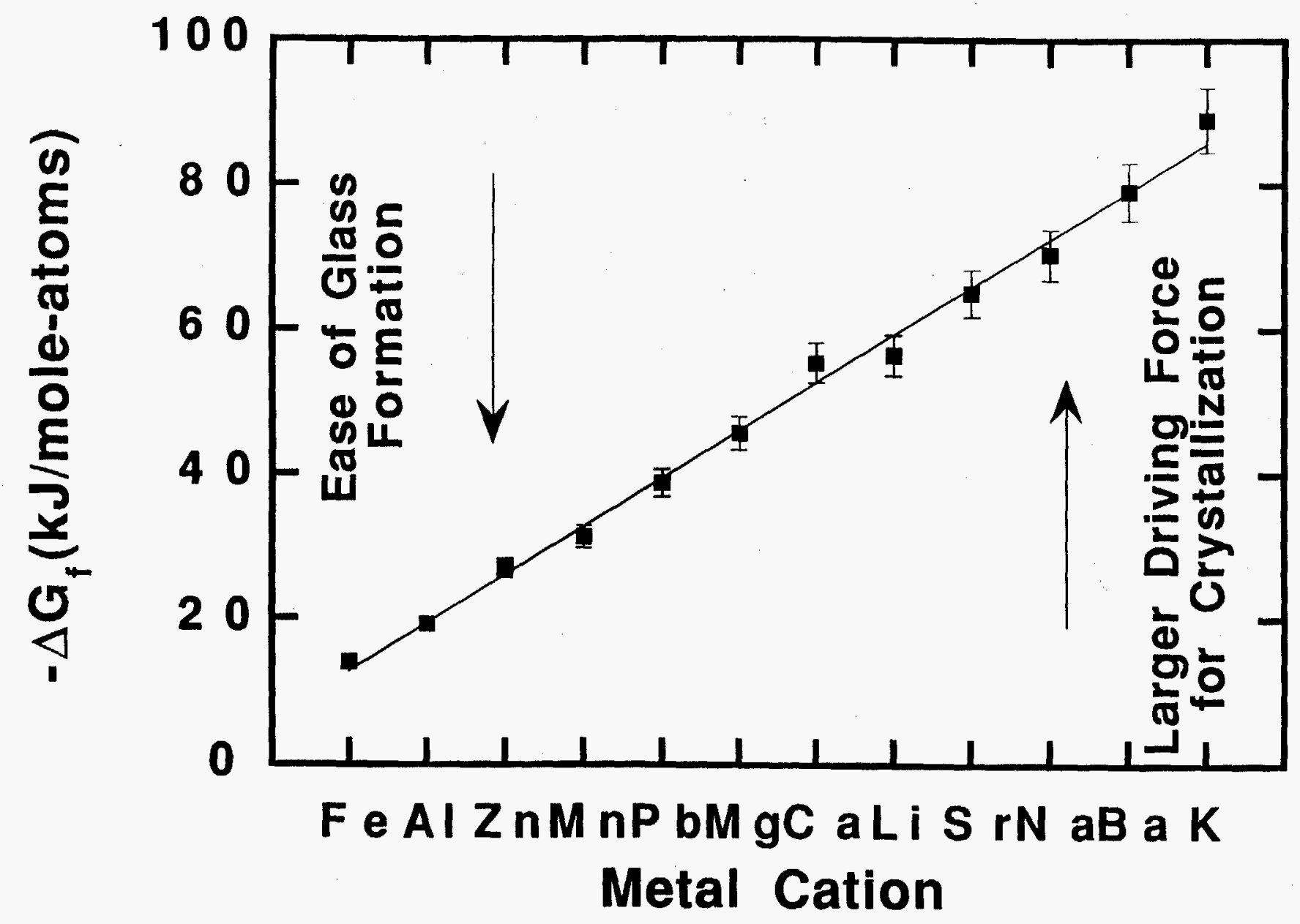

